\title{
ANALISA PENGARUH LAMA FERMENTASI DAN TEMPERATUR DISTILASI TERHADAP SIFAT FISIK (SPECIFIC GRAVITY DAN NILAI KALOR) BIOETANOL BERBAHAN BAKU NANAS (ANANAS COMOSUS) \\ Rudy Sutanto, Harisman Jaya, Arif Mulyanto \\ Jurusan Teknik Mesin Fakultas Teknik Universitas Mataram \\ Jln. Majapahit No.62 Mataram Nusa Tenggara Barat Kode Pos: 83125 \\ Telp. (0370) 636087; 636126; ext 128 Fax (0370) 636087
}

\begin{abstract}
Abstrak
Indonesia merupakan salah satu negara dengan luas areal perkebunan nanas terbesar di Asia selain Thailand, Filipina dan Malaysia yaitu mencapai lebih dari 165.690 hektar.Nanas juga merupakan salah satu jenis tanaman yang mengandung gula dan karbohidrat seperti halnya jagung, singkong, aren, dll yang biasa digunakan sebagai bahan baku pembuatan bioetanol. Oleh karena itu dalam kesempatan ini nanas akan digunakan sebagai bahan baku pembuatan bioetanol karena selain jumlahnya yang besar nanas juga memiliki potensi untuk dibuat menjadi bioetanol.

Penelitian ini bertujuan untuk mengetahui pengaruh dari waktu fermentasi dan temperatur distilasi sebagai variabel bebas terhadap specivic gravity dan nilai kalor bioetanol sebagai variabel terikat. Dalam penelitian ini waktu fermentasi yang digunakan adalah 5,7, dan 9 hari sedangkan temperatur distilasi adalah 60,75 , dan $80^{\circ} \mathrm{C}$. Pembuatan bioetanol dengan buah nanas ini dilakukan dengan proses fermentasi. Dalam proses pembuatannya setiap sampel yang massanya $1750 \mathrm{gr}$ ditambahkan ragi yang telah dibubukkan sebanyak $75 \mathrm{gr}$ atau sebanyak $4.3 \%$ massa sampel tersebut.

Dari penelitian ini didapatkan kadar alkohol meningkat dengan bertambahnya waktu fermentasi dan berbanding terbalik terhadap temperatur distilasi. Kadar alkohol tertinggi diperoleh sebesar 76,03 \% sedangkan yang terendah adalah 65,01 \% Specivic gravity menurun dengan bertambah lamanya fermentasi dan menurunnya temperatur distilasi. Specific gravity tertinggi yaitu 0,87098, sedangkan yang terendah adalah 0,84448. Nilai kalor meningkat seiring dengan bertambah lamanya fermentasi dan menurunnya temperatur distilasi. Nilai kalor tertinggi diperoleh sebesar 29679,47 J/gr sedangkan yang terendah adalah 13458,48 J/gr.
\end{abstract}

Kata kunci : Nanas; waktu fermentasi; temperatur distilasi; specivic gravity; nilai kalor.

\section{Abstract}

Indonesia is one of the countries which has a largest pineaple plantation in Asia, that is more than 165.690 hektare besides Thailand, Filipina, and Malaysia. Pineaple is one of the plants which contains karbohidrat and sugar as well as corn, cassava, sugar palm, etc. Thus in this occasion the pineaple will be used as material for producing bioetanol cause besides its quantity is large, it's potential to make bioetanol.

This research head for identify the efect of fermentation periode and distilation temperature as independent variable to the specific gravity and heating value as dependent variable. In this research the fermentation periode used are 5, 7, and 9 days while distilation temperature are 60,75 , and $80^{\circ} \mathrm{C}$. Producing of this pineaple bioetanol is doing by fermentation proses. In producing this pineaple bioetanol each sample which mass is $1750 \mathrm{gr}$ added with 75 gr crushed yeast or equal with $4,3 \%$ mass of sample.

From the research it's found that the alcohol content is increase with fermentation periode and decresing of distilation temperature. Specific gravity decrease with increasing of fermentation periode and decreasing of distilation temperature. Heating value is increase with increasing of fermentation periode and deacreasing of distilation temperature.

Keywords : Pineaple; fermentation periode; distilation temperature; specific gravity; heating value. 


\section{PENDAHULUAN}

Dalam kehidupan ini kita tidak dapat dipisahkan dari kebutuhan akan sesuatu yang dinamakan energi.Seperti yang kita ketahui bahwa sebagian besar sumber energi yang dimanfaatkan oleh umat manusia berasal dari bahan bakar fosilyang sifatnya tidak dapat diperbaharui (Unrenewable). Bisa kita bayangkan bahwa pada saat ini dimana kebutuhan energi dunia yang semakin meningkat apabila tidak didukung dengan usaha-usaha penemuan sumber energi baru sebagai pendukung kebutuhan energi dunia maka suatu saat nanti sumber energi yang berupa bahan bakar fosil tersebutakan habis dan apabila hal ini terjadi maka dampak yang ditimbulkan akan sangat fatal terhadap kehidupan kita.

\section{Untukmenghadapi}

tantangan kebutuhan energi yang semakin meningkat ini diusulkan penggunaan bioenergi sebagai sumber energi alternatif pengganti bahan bakar fosil. Salah satu bentuk bioenergi yang digunakan dan sekaligus akan kita bahas saat ini adalah bioetanol. Bioetanol atau dapat juga disebut sebagai ethyl alkohol $\left(\mathrm{C}_{2} \mathrm{H}_{5} \mathrm{OH}\right)$ tergolong sebagai bahan bakar bernilai oktan tinggi sehingga dapat menggantikan timbal sebagai peningkat nilai oktan bensin. Bioetanol sendiri dapat dibuat dari produk tumbuh-tumbuhan seperti misalnya nira,umbi-umbian, dan buahbuahan. Dalam kesempatan ini kita akan membahas bioetanol yang berasal dari buah-buahan, yaitu buah nanas.

Indonesia merupakan salah satu Negara dengan luas areal perkebunan nanas terbesar di Asia selain Thailand, Filipina dan Malaysia yaitu mencapai lebih dari 165.690 hektar.Nanas merupakan salah satu jenis tanaman yang banyak mengandung gula yaitu sekitar 15 hingga $20 \%$. Oleh karena itu, nanas berpotensi sebagai bahan baku dalam memproduksi bioetanol. Pembuatan bioetanol dengan buah nanas ini kita lakukan dengan proses fermentasi menggunakan ragi tape. Kita memilih ragi tapeuntuk membantu proses fermentasi dengan alasan karena ragi tape selain mudah didapatkan juga ekonomis dalam segi harga.

\section{LANDASAN TEORI}

\subsection{Bahan Bakar}

Bahan bakar adalah materi yang bisa diubah menjadi energi.Biasanya bahan bakar mengandung energi panas yang dapat dilepaskan dan dimanipulasi. Kebanyakan bahan bakar digunakan manusia melalui proses pembakaran (reaksi redoks) dimana bahan bakar tersebut akan melepaskan panas setelah direaksikan dengan oksigen di udara. Proses lain untuk melepaskan energi dari bahan bakar adalah melalui reaksieksotermal dan reaksi nuklir (seperti Fisi nuklir atau Fusi nuklir). Hidrokarbon (termasuk di dalamnya bensin dan solar) sejauh ini merupakan jenis bahan bakar yang paling sering digunakan manusia.Bahan bakar lainnya yang bias dipakai adalah logam radioaktif (Anonim 5,2012).

Secara khusus bahan bakar didefinisikan sebagai senyawa kimia yang terutama tersusun dari karbon dan hidrogen yang bila direaksikan dengan oksigen pada suhu dan tekanan tertentu akan menghasilkan produk berupa gas dan sejumlah energi.

\subsection{Sifat-sifat bahan bakar cair}

\subsubsection{Nilai kalor}

Nilai kalor (heating value) merupakan salah satu sifat dasar yang penting dari bahan bakar yang dianggap sebagai energi dalam bentuk kalor yang ditransfer ketika produk dari pembakaran sempurna suatu sampel bahan bakar didinginkan sampai temperatur mula-mula dari bahan bakar.

Nilai kalor berbandingterbalik dengan berat jenis. Pada volume yangsama, semakin besar berat jenis suatu minyaksemakin kecil nilai kalornya, demikian jugasebaliknya semakin rendah berat jenis semakintinggi nilai kalornya. Sebagai contoh adalahberat jenis bahan bakar diesel lebih tinggidaripada bahan bakar bensin sehingga nilai kalordari bahan bakar diesel lebih rendah daripadabahan bakar bensin (Kusuma,2010).

Nilai kalor bahan bakar dapat dibedakan menjadi dua, yaitu nilai kalor atas dan nilai kalor bawah.

\section{- Nilai kalor atas}

Kuantitas yang dikenal sebagai nilai kalor atas (Higher Heating Value) ditentukan dengan cara mendinginkan hasil atau produk pembakaran yang berupa gas panas ke temperatur asal sebelum pembakaran dilakukan, dimana dalam perhitungannya dilibatkan juga kalor laten penguapan air. Pengukuran ini sering 
dilakukan dengan mendinginkan produk hingga temperaturlingkungan.

\section{- Nilai kalor bawah}

Kuantitas yang dikenal sebagai nilai kalor bawah (Lower Heating Value) ditentukan dengan cara mengurangkan kalor laten penguapan air dari nilai kalor atas. Perhitungan nilai kalor bawah mengasumsikan bahwa komponen air dari suatu proses pembakaran tetap berada dalam keadaan uap pada akhir proses pembakaran, yang mana hal ini berlawanan dengan yang disebutkan pada nilai kalor atas yang mengasumsikan bahwa komponen air dalam proses pembakaran kembali kedalam keadaan cair setelah terjadi penguapan selama proses pembakaran. Nilai kalor bawah juga mengasumsikan bahwa kalor laten penguapan dari air dalam bahan bakar dan produk reaksi tidak dipulihkan (Anonim 6,2012).

Untuk menghitung nilai kalor dapat digunakan rumus-rumus sebagai berikut (Anonim 4,2007)

$$
\begin{aligned}
& N K A=\frac{\left\lfloor\left(m_{a}+m_{k}\right) \times C_{p a} \times \Delta T\right]-[y \times N K p]}{m_{b b}}(\mathrm{~J} / \mathrm{gr}) \\
& \text { Dan } \\
& N K B=N K A-X_{\mathrm{H}_{2} \mathrm{O}} \cdot L_{\mathrm{H}_{2} \mathrm{O}}(\mathrm{J} / \mathrm{gr})
\end{aligned}
$$

Keterangan :

NKA : nilai kalor atas bahan bakar

NKB : nilai kalor bawah bahan bakar

$X_{H_{2} O}$ : massa air yang terkondensasi

$\mathrm{L}_{\mathrm{H}_{2} \mathrm{O}}$ : konstanta panas laten $\mathrm{H}_{2} \mathrm{O}$ pada $25^{\circ} \mathrm{C}=2442 \mathrm{~J} / \mathrm{gr}$

$m_{a} \quad$ : massa air dalam bejana (gr)

$m_{k} \quad$ : nilai tara air calorimeter (gr)

$C_{p a} \quad$ : panas jenis air $\left(\mathrm{J} / \mathrm{gr}^{\circ} \mathrm{C}\right)$

$m_{b \varepsilon}$ : massa bahan bakar yang dijadikan sampel (gr)

$\Delta T_{a} \quad$ : kenaikan suhu yang terkoreksi $\left({ }^{\circ} \mathrm{C}\right)$

$N K K$ : nilai kalor pemantik, yaitu 9,62 $\mathrm{J} / \mathrm{cm}$

y $\quad$ : panjang kawat terbakar $(\mathrm{cm})$

\subsubsection{Specific gravity}

Specific gravity didefinisikan sebagai perbandingan berat dari sejumlah volume bahan bakar terhadap berat air untuk volume yang sama pada suhu tertentu. Densitas bahan bakar relatif terhadap airdisebut specific gravity.

Hubungan antara specific gravity (SG) dan densitas dapat dilihat pada persamaan dibawah ini :

$S G=\frac{\rho_{\text {substanst }}}{\rho_{\text {air(water } r)}}$

Dimana :

$\rho_{\text {substansi }}=$ densitas substansi yang diukur $\left(\mathrm{kg} / \mathrm{m}^{3}\right)$

$\rho_{\text {substansi }}=$ densitas air $\left(\mathrm{kg} / \mathrm{m}^{3}\right)$

Karakteristik ini berkaitan dengan besarnya nilai kalor dan daya yang dihasilkan oleh bahan bakar per satuan volume bahan bakar.

Specific gravity (SG) air ditentukan sama dengan satu. Karena specific gravity adalah perbandingan, maka specific gravitytidak memiliki satuan.Pengukuran specific gravity biasanya dilakukan dengan hydrometer.Specific gravity digunakan dalam perhitungan yang melibatkan berat dan volume (Anonim2,2004).

\subsection{Bomb kalorimeter}

Bombkalorimeter adalah alat yang digunakan untuk mengukur jumlah kalor (nilai kalori) yang dibebaskan pada pembakaran sempurna (dalam $\mathrm{O}_{2}$ berlebih) suatu senyawa, bahan makanan, bahan bakar. Sejumlah sampel ditempatkan pada tabung beroksigen yang tercelup dalam medium penyerap kalor (kalorimeter)dan sampel akan terbakar oleh api listrikyang dilewatkan dari kawat logamyang terpasang dalam tabung.

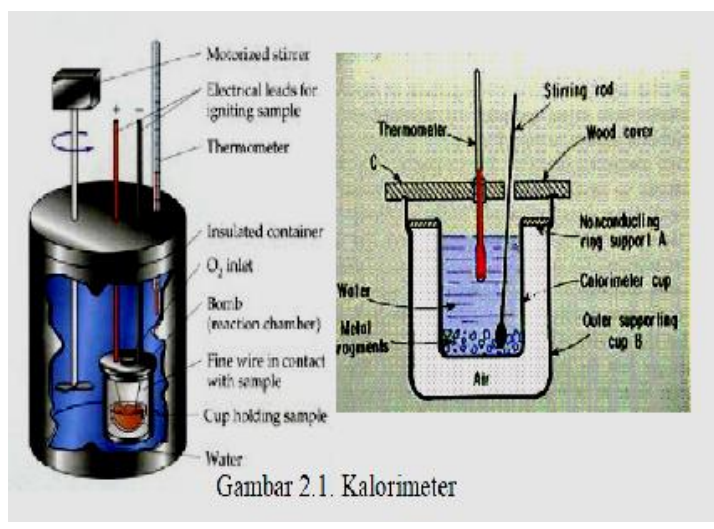

2.4 Etanol

Etanol, disebut juga etil alkohol, alkohol murni, alkohol absolut, atau alkohol saja, adalah sejenis cairan yang mudah menguap, mudah terbakar, tak berwarna, 
dan merupakan alkohol yang paling sering digunakan dalam kehidupan sehari-hari. Senyawa ini merupakan obat psikoaktif dan dapat ditemukan pada minuman beralkohol dan termometermodern.

Etanol termasuk ke dalam alkohol rantai tunggal, dengan rumus kimia $\mathrm{C}_{2} \mathrm{H}_{5} \mathrm{OH}$ dan rumus empiris $\mathrm{C}_{2} \mathrm{H}_{6} \mathrm{O}$.la merupakan isomer konstitusional dari dimetil eter. Etanol sering disingkat menjadi $\mathrm{EtOH}$, dengan "Et" merupakan singkatan dari gugus etil $\left(\mathrm{C}_{2} \mathrm{H}_{5}\right)$.

\subsection{Proses produksi bioetanol}

\subsubsection{Fermentasi}

Fermentasi berasal dari bahasa latin yaitu ferfere yang artinya mendidihkan, yaitu berdasarkan ilmu kimia terbentuknya gas-gas dari suatu cairan kimia yang pengertiannya berbeda dengan air mendidih. Gas yang terbentuk di antaranya karbondioksida (CO2) (Afrianti,2004).

Fermentasi sebenarnya merupakan kegiatan mengaktifkan pertumbuhan dan metabolisme dari mikroba, membentuk alkohol dan asam, serta menekan pertumbuhan mikroba proteolitik dan lipolitik. Beberapa hasil fermentasi terutama asam dan alkohol dapat mencegah pertumbuhan mikroba yang bersifat racun didalam makanan, misalnya Clostridium botulinum (Winarno, 1984).

Apabila suatu mikroba ditumbuhkan dalam media pati, maka pati tersebut akan diubah oleh enzimamilase yang dikeluarkan oleh mikroba tersebut menjadi maltosa. Maltosa dapat dirombak menjadi glukosa oleh enzim maltase.Kemudian glukosa oleh enzim zimase dirombak menjadi alkohol, sedangkan alkohol oleh enzim alkoholase dapat diubah menjadi asam asetat. Asam asetat ini akan dirombak oleh enzim oksidase menjadi karbondioksida dan air (Tarigan,1988).

\subsubsection{Distilasi}

Jika etanol ingin digunakan sebagai bahan bakar, maka sebagian besar kandungan airnya harus dihilangkan melalui proses distilasi. Tingkat kemurnian etanol setelah didistilasi masih sekitar 9596\% (masih ada kandungan airnya 3-4\%). Campuran ini dinamakan etanol hidrat dan bisa digunakan sebagai bahan bakar, tapi tidak bisa dicampur sama sekali dengan bensin. Jadi, biasanya kandungan air dalam etanol hidrat dibuang habis terlebih dahulu dengan pengolahan lainnya sehinggabisa dicampurkan dengan bensin.

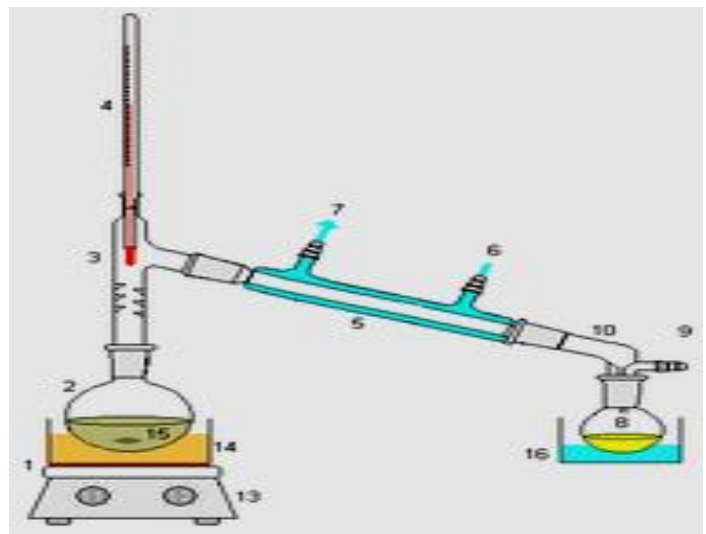

Gambar 2.2.peralatan Destilasi

Berikut adalah susunan rangkaian alat ditilasi sederhana:

1. wadah air

2. labu distilasi

3. sambungan

4. termometer

5. kondensor

6. aliran masuk air dingin

7. aliran keluar air dingin

8. labu distilat

9. lubang udara

10.tempat keluarnya distilat

11. penangas

12. air penangas

13. larutan zat

Beberapa hal penting yang harus diperhatikan dalam destilasi adalah kondisi saat pemanasan labu didih. Dalam keadaan suhu dan tekanan tinggi, labu dapat mengalami ledakan yang dikenal sebagai super heated. Secara teknis, sebelum proses pemanasan, di dalam labu didih disertakan agen anti bumping seperti pecahan porcelain. Pori-pori porcelain dapat menyerap panas dan meratakan panas ke seluruh sistem. Metode destilasi digunakan pada larutan yang mempunyai titik didih moderat sekitar $100^{\circ} \mathrm{C}$. Apabila terdapat sampel dengan titik didih sangat tinggi, tidak disarankan menggunakan teknik pemisahan destilasi karena dua hal yaitu suhu dan tekanan tinggi rawan ledakan dan pada suhu tinggi senyawa dapat mengalami dekomposisi atau rusak (Anonim 9,2012). 


\subsection{Ragi}

Ragi tape adalah bahan yang dapat digunakan dalam pembuatan tape,baik dari singkong maupun beras ketan. Menurut Tarigan (1988)ragi tape merupakan populasi campuran yang tediri dari spesies-spesies genus Aspergilius, Saccharomyces, Candida, Hansenulla, dan bakteri Acetobacter.Genus tersebut hidup bersamasama secara sinergis. Aspergillus menyederhanakan tepung menjadi glukosa serta memproduksi enzim glukoamilase yang akan memecah pati dengan mengeluarkan unit-unit glukosa,sedangkan Saccharomyces, Candida dan Hansenulla dapat menguraikan gulamenjadi alkohol dan bermacam-macam zat organik lain sementara itu Acetobacter dapat merombak alkohol menjadi asam. Beberapa jenis jamur juga terdapat dalamragi tape, antara lain Chlamydomucor oryzae, Mucor sp, dan Rhizopus sp.

Menurut Maimuna(2004) Khamir merupakan fungi bersel tunggal sederhana, kebanyakan bersifat saprofitik dan biasanya terdapat dalam tumbuh-tumbuhan yang mengandung karbohidrat.Khamir dapat diisolasi dari tanah yang berasal dari kebun buahbuahan dan biasanya khamir berada di dalam cairan yang mengandung gula, seperti cairan buah, madu, sirup, dan sebagainnya.Bentuk sel khamir biasanya bulat, oval, dan biasanya tidak mempunyai flagella. Pada umumnya khamir berkembang biak dengan bertunas, membelah diri dan pembentukan spora.

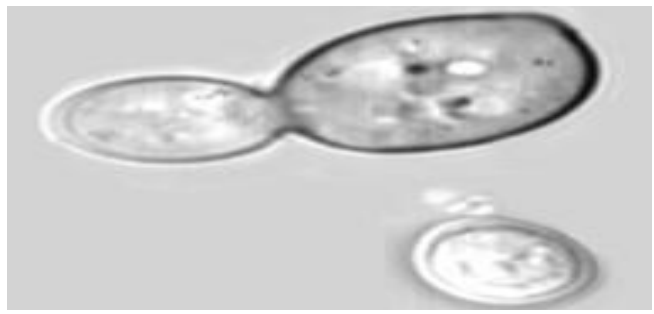

Gambar 2.3 Saccharomyces cerevisiae

Pada umumnya kisaran suhu pertumbuhan untuk khamir adalah samadengan suhu optimum pada kapang sekaitar 25-30 ${ }^{\circ} \mathrm{C}$ dan suhu maksimum kirakira $\quad 35-47^{\circ} \mathrm{C}$. Sementara itu pertumbuhan khamir pada umumnya lebih baik pada suasana asam dengan $\mathrm{pH} 4-4,5$, dan tidak dapat tumbuh dengan baik pada medium alkali, kecuali jika telah beradaptasi. Khamir tumbuh pada kondisi aerobic, tetapi yang bersifat fermentatif dapat tumbuh secara anaerobic meskipun lambat (Fardiaz, 1992).

\section{Saccharomyces} cerevisiae merupakan spesies yang bersifat fermentatif kuat.Tetapi dengan adanya oksigen, Saccharomyces cerevisiae juga dapatmelakukan respirasi yaitu mengoksidasi gula menjadi karbondioksida dan air.Kedua sistem tersebut menghasilkan energi, meskipun yang dihasilkan darirespirasi lebih tinggi dibandingkan dengan melalui fermentasi.Saccharomycescerevisiae akan mengubah $70 \%$ glukosa di dalam substrat menjadikarbondioksida dan alkohol, sedangkan sisanya tanpa ada nitrogen diubahmenjadi produk penyimpanan cadangan. Produk penyimpanan tersebut akan digunakan lagi melalui proses fermentasi endogenous jika glukosa di dalam medium sudah habis (Fardiaz,1992).

Pada dasarnya proses pembuatan ragi tape sangat sederhana dengan bahanbahan yang mudah didapat dan pembuatannya tidak membutuhkan waktu yang cukup lama. Bahan-bahan yang digunakan adalah laos, tebu kuning atau gula pasir, ubi kayu dan jeruk nipis. Adapun proses pembuatannya yaitu bahan-bahan tersebut dikupas dan dicuci, kemudian dihaluskan lalu dicampur dengan tepung beras atau tepung malt, ditambah sedikit air sampai terbentuk adonan.Kemudian didiamkan dalam suhu kamar selama 3 hari dalam keadaan terbuka, sehingga adonan akan ditumbuhi kapang Chlamydomucor oryzae secara alami. Kemudian pisahkan kotorannya dan diperas untuk mengurangi airnya lalu dibuat bulatan-bulatan dan dikeringkan (Anonim,1,1980).

\subsection{Nanas}

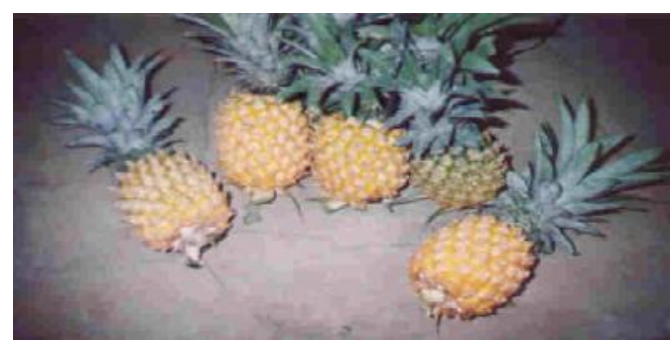

Gambar 2.4 Nanas

Tanaman nanas mempunyai nama botani Ananas comosus (L.) Merr.Tanaman nanas jika diklasifikasikan termasuk 
tanaman berbunga. Klasifikasi dari tanaman nanas adalah sebagai berikut :

\begin{tabular}{ll} 
Kingdom & : Plantae \\
Subkingdom & : Tracheobionta \\
Divisi & : Magnoliophyta \\
Kelas & : Liliopsida \\
Ordo & : Farinosae \\
Subordo & : Comelinidae \\
Fanilia & : Bromeliaceae \\
Genus & : Ananas \\
Spesies & : Ananas comosus \\
\multicolumn{2}{c}{ Nanas tumbuh di }
\end{tabular}
agroklimat sehingga tanaman ini tersebar luas.Idealnya, nanas tumbuh ditempat yang ketinggiannya $100-1000 \mathrm{~m}$ dpl dengan suhu rata-rata $21-30^{\circ} \mathrm{C}$.Curah hujan yang dibutuhkan $635-2500 \mathrm{~mm}$ per tahun dengan bulan basah (curah hujan $>200 \mathrm{~mm}$ ) 3-4 bulan.Disamping itu juga memerlukan pencahayaan matahari 33-71 $\%$ dari pencahayaan maksimum dengan angka tahunan rata-rata 2000 jam. Umumnya nanas toleran terhadap kekeringan. $\mathrm{Di}$ daerah beriklim kering dengan 4-6 bulan kering tanaman nanas masih mampu berbuah, asalkan daerah tersebut memiliki kedalaman air yang cukup, yakni $50-150 \mathrm{~cm}$. Nanas memiliki akar yang dangkal tetapi mampu menyimpan air (Anonim 3,2004).

\section{METODE PENELITIAN}

\subsection{Tempat penelitian}

Penelitian dilakukan dibeberapa tempat yang memiliki peralatan penunjang, diantaranya :

1. Laboratorium Kimia Bahan Pangan jurusan IImu Nutrisi dan Makanan Ternak Fakultas Peternakan Universitas Mataram untuk pengujian nilai kalor.

2. Laboratorium Kimia Analitik Fakultas MIPA Universitas Mataram untuk pengujian specific gravity dan distilasi.

\subsection{Alat dan Bahan}

\subsubsection{Alat penelitian}

Alat-alat yang digunakan dalam penelitian ini adalah :

1. Peralatan pengujian Nilai kalor :
a) 1341 Adiabatik bomb kalorimeter
b) Tabung oksigen
c) Timbangan digital
d) Pipet
e) Termometer
f) Penggaris
g) Kawat pijar (pemantik)
h) Cawan
i) Gelas ukur
j) Pinset

2. Peralatan pengujian Specific grafity :
a) Gelas ukur kecil
b) Timbangan digital Sartorius
c) Botol plastik
d) Termometer digital

\subsubsection{Bahan penelitian}

1. Bahan produksi alkohol
a) Ekstrak nanas
b) Ragi / yeast

2. Bahan pengujian sifat fisik

Bahan yang digunakan dalam pengujian sifat fisik ini adalah bioetanol yang terbuat dari ekstraknanas.

\subsection{Tahap pembuatan bioetanol \\ 3.3.1. Persiapan fermentasi}

1. Pembuatan media fermentasi dari Nanas

Nanas yang sudah dikupas dibersihkan dan dipisahkan dari bonggolnya kemudian dihancurkan dengan blender. Dalam proses penghancuran dengan blender ini buah nanas yang sudah dipersiapkan dimasukkan kedalam blender sesuai kapasitas blender kemudian ditambahkan air selanjutnya blender dihidupkan selama kurang lebih satu menit. Setelah itu blender dimatikan dan nanas yang sudah hancur kemudian ditempatkan pada wadah yang sudah disediakan.Untuk proses pemblenderan selanjutnya dilakukan dengan cara yang sama hanya saja tidak ditambahkan air lagi melainkan air digantikan oleh cairan nanas yang sudah diblender lebih dulu, hal ini dilakukan untuk meminimumkan air yang ikut terbawa dalam bahan yang akan difermentasikan .

2. Mengatur volume bahan

Untuk mengatur volume bahan digunakan gelas ukur sebagai takaran.Volume bahan baku fermentasi sebanyak 14 liter dibagi kedalam sembilan bagian untuk menjadi sampel, dimana setiap bagian memiliki volume 1,5 liter.

\subsubsection{Proses fermentasi}

Setelah volume bahan (dalam bentuk bubur) atau sampel ditentukan kemudian dilakukan fermentasi terhadap sampel, yaitu dengan menambahkan ragi 
tape yang telah dihaluskan kedalam sampel tersebut sebanyak $75 \mathrm{gram}$ atau sebanyak $4,3 \%$ dari massa sampel yang besarnya $1750 \mathrm{gr}$. Jumlah ragi untuk setiap sampel disamakan. Setelah proses peragian selesai wadah tempat fermentasi kemudian ditutup rapat dan dibiarkan pada lama fermentasi yang telah ditentukan.

Setelah proses fermentasi berakhir langkah selanjutnya adalah pengambilan cairan fermentasi dimana proses ini dilakukan dengan cara memeras bahan fermentasi yang tadinya berbentuk bubur untuk dipisahkan antara cairan ekstraknya dengan serat/ampasnya yang berupa padatan.

\subsubsection{Proses distilasi}

Setelah diproleh cairan hasil fermentasi kemudian dilakukan proses distilasi untuk memperoleh bioetanol.

\subsubsection{Diagram Alir Penelitian}

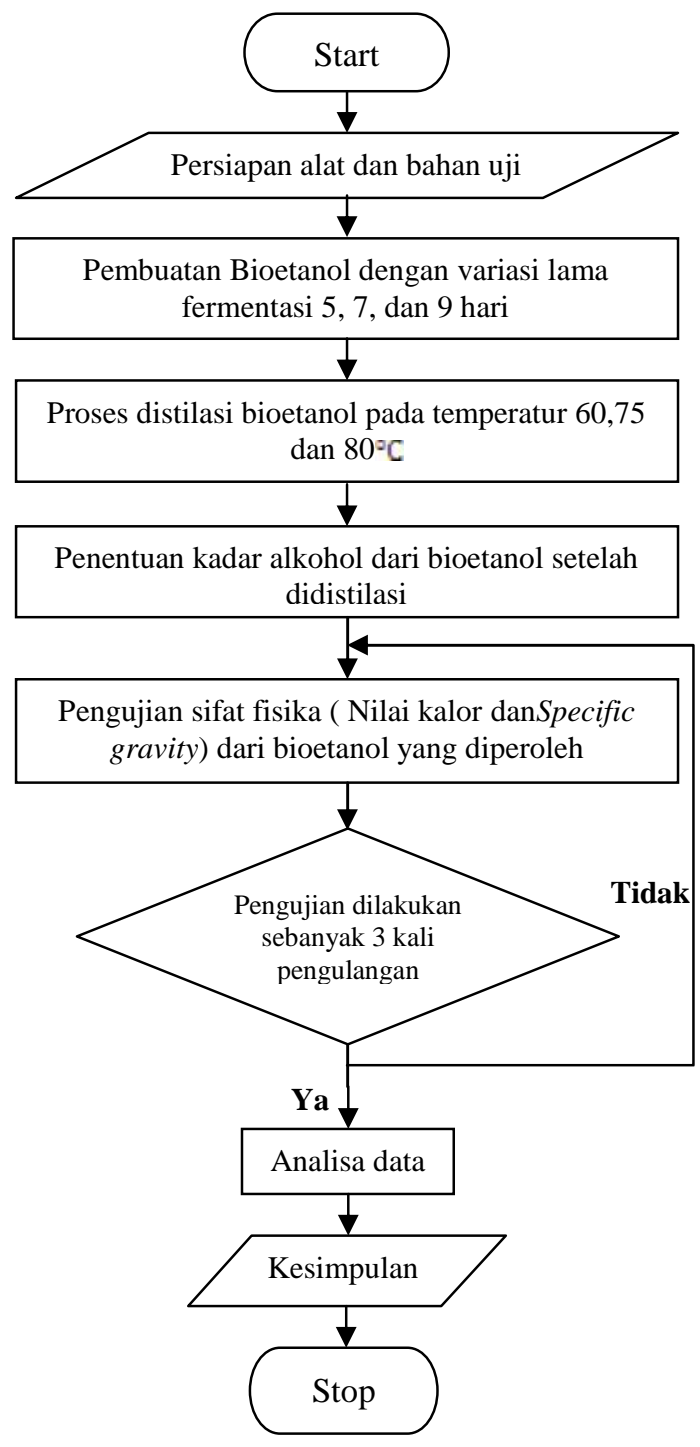

HASIL DAN PEMBAHASAN.

\subsection{Penentuan kadar alkohol}

Untuk lebih jelasnya hasil pengujian pengaruh waktu fermentasi dan temperatur distilasi dapat kita lihat pada tabel dibawah ini :

Tabel 4.1 pengaruh waktu fermentasi dan temperatur distilasi terhadap kadar alkohol

\begin{tabular}{|c|c|c|c|}
\hline $\begin{array}{c}\text { Lama } \\
\text { Fermentasi } \\
\text { (hari) }\end{array}$ & $\begin{array}{c}\text { Temperatur } \\
\text { distilasi (-c) }\end{array}$ & $\begin{array}{c}\text { Volume } \\
\text { akhir } \\
\text { distilat } \\
\text { (alkohol) } \\
\text { (ml) }\end{array}$ & $\begin{array}{c}\text { Kadar } \\
\text { alkohol } \\
\text { (\% wt) }\end{array}$ \\
\hline 5 & 60 & 64 & 73,61 \\
\hline 7 & 60 & 52,3 & 74,90 \\
\hline 9 & 60 & 51 & 76,03 \\
\hline \multicolumn{4}{|l|}{} \\
\hline 5 & 75 & 86,3 & 65,92 \\
\hline 7 & 75 & 75 & 71,48 \\
\hline 9 & 75 & 58,3 & 73,19 \\
\hline \multicolumn{5}{|l|}{} \\
\hline 5 & 80 & 95 & 65,01 \\
\hline 7 & 80 & 95,7 & 67,74 \\
\hline 9 & 80 & 87 & 72,79 \\
\hline
\end{tabular}

Dalam tabel diatas kadar alkohol dan volume dituliskan dalam nilai rata-rata dari tiga kali pengulangan yang dilakukan selama pengujian.

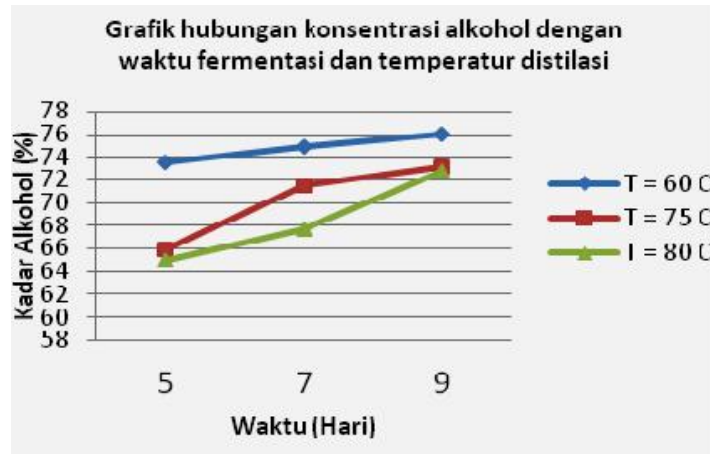

Gambar 4.1

Alkohol diperoleh melalui fermentasi karbohidrat dengan bantuan katalis (ragi). Dimana selama proses tersebut sekumpulan bakteri yang terdapat didalam ragi akan menguraikan karbohidrat menjadi glukosa yang kemudian glukosa diuraikan menjadi alkohol yang merupakan salah satu dari produk fermentasi yang kita harapkan dalam panelitian ini.

Dari tabel 4.1 dan gambar 4.1 ditunjukkan bahwa semakin lama fermentasi 
berlangsung alkohol yang dihasilkan juga akan semakin banyak. Dalam gambar 4.1 diperlihatkan bahwa kadar alkohol tertinggi diperoleh pada waktu fermentasi 9 hari selanjutnya diikuti oleh waktu fermentasi 7 hari dan yang paling rendah adalah pada waktu 5 hari. Seperti yang sudah dijelaskan, jumlah mikroba antara lain dipengaruhi oleh waktu fermentasi, yakni semakin lama fermentasi berlangsung jumlah mikroba juga akan semakin banyak sehingga alkohol yang dihasilkan juga semakin banyak. Proses ini akan terhenti jika kadar alkohol sudah meningkat sampai tidak dapat ditolerir lagi oleh mikroba.

Disamping itu jika kita perhatikan kembali peda grafik diatas kita akan melihat bahwa temperatur distilasi juga memiliki pengaruh terhadap kadar alkohol. Dari pengujian yang dilakukan terlihat bahwa antara temperatur distilasi dengan kadar alkohol terdapat hubungan keterbalikan dalam arti apabila distilasi berlangsung pada temperatur yang relatif tinggi misalnya pada temperatur $80^{\circ} \mathrm{C}$ maka kadar alkohol yang didapatkan akan lebih rendah jika dibandingkan dengan proses distilasi yang dilakukan pada temperatur yang lebih rendah, misalnya $60^{\circ} \mathrm{C}$. Hal demikian terjadi karena pada proses distilasi yang berlangsung pada temperatur yang lebih tinggi akan terdapat jumlah air yang lebih banyak menyertai alkohol dibandingkan apabila proses tersebut dilakukan pada temperatur yang lebih rendah. Oleh karena itu perbandingan antara alkohol dengan air pada hasil distilasi yang dilakukan pada temperatur yang tinggi akan bernilai lebih kecil jika dibandingkan dengan perbandingan alkohol dengan air pada hasil distilasi yang diperoleh melalui proses distilasi pada temperatur yang rendah.

\subsection{Perhitungan Specific grvity (SG)}

Tabel 4.2 Hasil pengukuran massa dan densitas aquades

\begin{tabular}{|c|c|c|c|}
\hline $\begin{array}{c}\text { Nama } \\
\text { substansi }\end{array}$ & $\begin{array}{c}\text { Volume } \\
\text { (ml) }\end{array}$ & $\begin{array}{c}\text { Massa } \\
\text { (gr) }\end{array}$ & $\begin{array}{c}\text { Densitas } \\
\text { (gr/ml) }\end{array}$ \\
\hline Aquades & 25 & 24,0552 & 0,9622 \\
\hline Aquades & 25 & 24,0734 & 0,9629 \\
\hline Aquades & 25 & 24,1107 & 0,9644 \\
\hline Rata-rata & $\mathbf{2 5}$ & $\mathbf{2 4 , 0 7 9 8}$ & $\mathbf{0 , 9 6 3 2}$ \\
\hline
\end{tabular}

Perhitungan untuk data pengujian bioetanol dengan lama fermentasi 5 hari dan temperatur distilasi $60^{\circ}$ Cadalah sebagai berikut.

Diketahui : Densitas etanol $=0,81906 \mathrm{gr} / \mathrm{ml}$ Volume $\quad=25 \mathrm{ml}$

Densitas Air $\quad=0,9632 \mathrm{gr} / \mathrm{ml}$

$$
\begin{aligned}
& S G=\frac{\text { Densitas etanol }}{\text { Densitas air }} \\
& S G=\frac{0,81906}{0,9632}=0,85035
\end{aligned}
$$

Untuk perhitungan selanjutnya dilakukan dengan cara yang sama seperti diatas dan hasilnya ditabelkan sebagai berikut.

Tabel 4.3 Nilai rata-rata densitas dan specific gravity pada tiap variasi lama fermentasi dan temperatur distilasi

\begin{tabular}{|c|c|c|c|}
\hline $\begin{array}{c}\text { Lama } \\
\text { fermentasi } \\
\text { (Hari) }\end{array}$ & $\begin{array}{c}\text { Temperstur } \\
\text { Distilasi } \\
\left({ }^{\circ} \mathrm{c}\right)\end{array}$ & $\begin{array}{c}\text { Densitas } \\
\text { rata-rata } \\
(\mathbf{g r} / \mathbf{m l})\end{array}$ & $\begin{array}{c}\text { Specivic } \\
\text { Gravity }\end{array}$ \\
\hline 5 & 60 & 0,81906 & 0,85036 \\
\hline 5 & 75 & 0,83681 & 0,86879 \\
\hline 5 & 80 & 0,83893 & 0,87098 \\
\hline \multicolumn{4}{|l}{} \\
\hline 7 & 60 & 0,81604 & 0,84722 \\
\hline 7 & 75 & 0,82404 & 0,85552 \\
\hline 7 & 80 & 0,83267 & 0,86448 \\
\hline \multicolumn{5}{|l|}{} \\
\hline 9 & 60 & 0,81340 & 0,84448 \\
\hline 9 & 75 & 0,82006 & 0,85139 \\
\hline 9 & 80 & 0,82096 & 0,85233 \\
\hline
\end{tabular}

Nilai densitas dan specific gravity pada tabel diatas adalah nilai rata-rata dari tiga kali pengulangan. Data selengkapnya dapat dilihat pada lampiran 1.

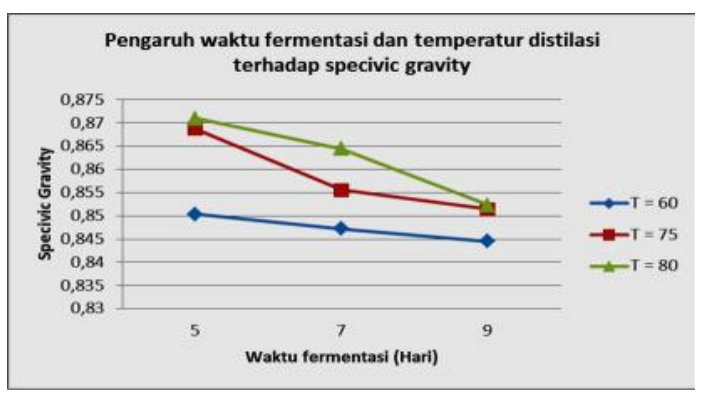

Gambar 4.2

Pada tabel 4.3 dan gambar 4.2 ditunjukkan pengaruh lama fermentasi dan temperatur distilasi terhadap specivic gravity dari 
alkohol yang dihasilkan. Dari pengujian yang dilakukan ditemukan bahwa lama fermentasi memiliki pengaruh terhadap specivic grvity alkohol yang diuji dimana pengaruh tersebut berupa suatu penurunan dalam nilai specivic gravity seiring bertambahnya waktu. Seperti yang kita ketahui sebelumnya bahwa semakin lama fermentasi berlangsung maka jumlah mikroba yang dibutuhkan dalam proses tersebut juga akan semakin bertambah, sehingga dengan semakin meningkatnya jumlah mikroba maka semakin banyak pula karbohidrat yang terurai menjadi alkohol. Dengan menigkatnya jumlah alkohol ini maka secara otomatis berat atau densitas daripada campuran alkohol-air akan semakin rendah yang mana hal ini juga yang menyebabkan specivic gravity dari campuran tersebut memiliki nilai yang rendah.

Selain itu temperatur juga memiliki pengaruh terhadap specivic gravity, hanya saja hubungan yang terjadi antara specivic gravity dengan temperatur berlangsung secara sebanding, artinya, semakin tinggi temperatur akan semakin tinggi pula nilai specivic gravity. Hal ini disebabkan karena ketika distilasi dilakukan pada temperatur yang tinggi misalnya $80^{\circ} \mathrm{C}$ maka jumlah air yang menyertai alkohol juga akan tinggi begitu juga sebaliknya dan oleh karenanya densitas dari pada hasil distilasi juga akan tinggi. Berhubung specivic gravity merupakan perbandingan antara densitas substansi terhadap densitas air, maka jelaslah bahwa apabila densitas substansi semakin tinggi maka specivic gravity juga akan tinggi.

\subsection{Perhitungan Nilai kalor (NK)}

Untuk Etanol 65,014\% (E 65,01) perhitungan Nilai kalor atas dan Nilai kalor bawah diberikan sebagai berikut :

$$
\begin{aligned}
& \text { NKA }=\frac{(2000+473) \times 4,179 \times 1,2-(8,0 \times 6,92)}{1,0705} \\
& N K A=11533,15 \mathrm{~J} / \mathrm{gr} \\
& \mathrm{NKB}=11533,15-(0,2080 \times 2442) \\
& \mathrm{NKB}=11025,21 \mathrm{~J} / \mathrm{gr} \\
& \quad \text { Untuk data selanjutnya perhitungan } \\
& \text { dilakukan dengan cara yang sama seperti } \\
& \text { perhitungan diatas dan hasilnya secara } \\
& \text { lengkap dapat dilihat pada lampiran } 2 .
\end{aligned}
$$

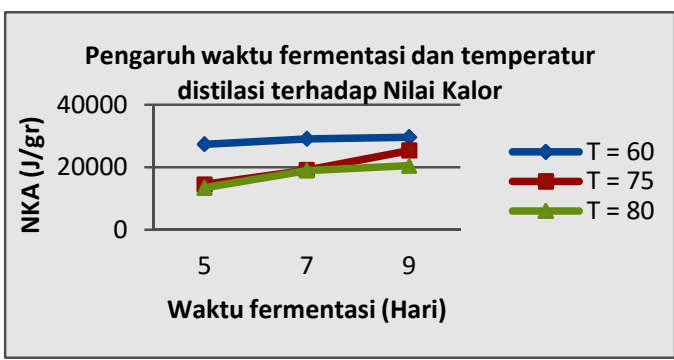

Gambar 4.3

Dari grafik diatas terlihat bahwa nilai kalor dari etanol yang dihasilkan menunjukkan peningkatan dengan semakin lamanya fermentasi dan menurunnya temperatur distilasi. Hal ini disebabkan karena semakin lama fermentasi berlangsung dan pada temperatur distilasi yang rendah maka kadar alkohol yang dihasilkan juga semakin tinggi. Dari hasil pengujian yang diperoleh terlihat bahwa semakin tinggi kadar alkohol, perbedaan temperatur yang dihasilkan akan semakin besar,dimana hal ini secara tidak langsung telah menunjukkan bahwa bioetanol yang memiliki kadar alkohol yang lebih tinggi cendrung akan melepaskan panas yang lebih besar jika dibandingkan dengan bioetanol dengan kadar yang lebih rendah.

Dari pengujian yang dilakukan didapatkan nilai kalor paling tinggi sebesar 29679,47 J/gr, nilai ini diperoleh pada variasi lama fermentasi 9 hari dengan temperatur distilasi sebesar $60^{\circ} \mathrm{C}$. Selanjutnya, nilai yang paling rendah diperoleh sebesar $13458,48 \mathrm{~J} / \mathrm{gr}$, nilai ini diperoleh pada variasi lama fermentasi 5 hari dengan temperatur distilasi sebesar $80^{\circ} \mathrm{C}$.

Dari hal tersebut diatas sekiranya dapat dipahami bahwa nilai kalor dipengaruhi oleh faktor-faktor yang juga mempengaruhi kadar alkohol, contohnya, pada penelitian ini adalah lama proses fermentasi dan temperatur distilasi. Namun yang perlu diperhatikan dalam hal ini adalah temperatur distilasinya, karena hal ini memiliki hubungan dengan jumlah etanol yang dihasilkan, dimana semakin tinggi temperatur semakin tinggi pula jumlah etanol yang diperoleh, tetapi kadarnya semakin rendah, oleh karena itu nilai kalornya juga akan rendah. 


\section{KESIMPULAN}

Dari penelitian yang dilakukan dapat diambil kesimpulan sebagai berikut :

1. Kadar etanol selain dipengaruhi oleh lama fermentasi juga dipengaruhi oleh temperatur distilasi,

2. Nilai specivic gravity yang diperoleh berbanding terbalik terhadap kadar alkohol yang didapat.

3. Nilai kalor dari etanol mengalami peningkatan seiring dengan peningkatan kadar etanol.

\section{SARAN}

Ikuti semua aturan yang berlaku dikampus agar proses pengerjaan tugas akhir berjalan lancar.

\section{DAFTAR PUSTAKA}

Afrianti,

$\mathrm{H}$.

L., $\quad 2004$

Fermentasi,http://www.forumsains.c om/index.php/topic, 783.msg2697.

Anonim 1, 1980, Pembuatan Ragi Tape, http://iptek.apjii.or.id/data/pangan/ka talog_ipb.htm.

Anonim 2, 2004,Bahan bakar dan pembakaran,www.energyefficiencya sia.org.

Anonim 3, 2004,TTG Budidaya Pertanian, http://www.warintek.ristek.go.id/pert anian/nenas.pdf.

Anonim 4, 2007, Bahan bakar, http://www.chemeng.ui.ac.id.

Anonim 5, 2012, Bahan bakar berdasarkan fasenya ${ }_{2}$ http://id. wikipedia.org/wiki/B ahan bakar.
Anonim 6,2012, Dasar pembakaran dan bahan bakar, http://en.wikipedia.org/wiki/Heat of combustion\#Heating value.

Anonim 9,2012, Proses produksi bioetanol, http://id.wikipedia.org/wiki/Bahan bakar etanol\#Sumber.

Fardiaz, S., 1992, Mikrobiologi Pangan 1, Jakarta: PT. Gramedia Utama Pustaka, hal 62, 105, 110, 245, 246, dan 235.

KusumaWijaya,Bagus I Gusti,2010,Pengolahan sampah organik menjadi etanol dan pengujian sifat fisika Biogasoline.

Maimuna, S., 2004, Pengaruh interaksi variasi suhu dan lama fermentasi terhadap kadarglukosa dan kadar alkohol tape ketan hitam, Malang:Skripsi tidak diterbitkan. Jurusan Biologi Fakultas Sains dan TeknologiUniversitas Islam Negeri Malang.

Tarigan, J., 1988, Pengantar Mikrobiologi Umum, Jakarta: Departemen Pendidikan dan Kebudayaan Direktorat Jenderal Pendidikan Tinggi Proyek Pengembangan Lembaga Pendidikan Tenaga Pendidikan.

Winarno, F.G,1984, Pengantar Teknologi Pangan, Jakarta: PT Gramedia. 